University of Wollongong

Research Online

Faculty of Engineering and Information

Faculty of Engineering and Information

Sciences - Papers: Part A

Sciences

$1-1-2014$

\title{
Mathematical modeling and experimental verification of fluid flow through deformable rough rock joints
}

Buddhima Indraratna

University of Wollongong, indra@uow.edu.au

Chandrasiri Kumara

University of Wollongong

Song-Ping Zhu

University of Wollongong, spz@uow.edu.au

Scott Sloan

University of Newcastle

Follow this and additional works at: https://ro.uow.edu.au/eispapers

Part of the Engineering Commons, and the Science and Technology Studies Commons

Research Online is the open access institutional repository for the University of Wollongong. For further information contact the UOW Library: research-pubs@uow.edu.au 


\title{
Mathematical modeling and experimental verification of fluid flow through deformable rough rock joints
}

\begin{abstract}
Rock joints exert an enormous influence on the permeability of a rock mass because they act as interconnecting networks that provide pathways for fluids to permeate and flow within the rock structure. The apertures in rock joints are irregular in nature and induce flows that cannot be described by the parallel-plate theory based on planar joints or the classical cubic flow relationships. In this study, a twodimensional (2D) hydraulic aperture distribution was considered to develop a mathematical model for fracture flow. In this approach, the three-dimensional Navier-Stokes equation was integrated over the joint aperture and converted to an equivalent 2D flow model. The proposed model was then solved numerically by adopting a well-known algorithm for coupling the pressure and velocity and implementing it in a computer program. The selected program is capable of predicting the deformation of the joint apertures on normal loading, the resulting flow patterns, and the volumetric flow rates associated with permeability tests conducted using a high-pressure triaxial apparatus that was designed and built at the University of Wollongong. The model output for different conditions of confining stresses and hydraulic gradients was computed, and a good agreement with the experimental results was observed.

\section{Disciplines}

Engineering | Science and Technology Studies

\section{Publication Details}

Indraratna, B., Kumara, C., Zhu , S. \& Sloan, S. (2014). Mathematical modeling and experimental verification of fluid flow through deformable rough rock joints. International Journal of Geomechanics, 15 (4), 04014065-1-04014065-11.
\end{abstract}




\title{
Mathematical Modelling and Experimental Verification of Fluid Flow through Deformable Rough Rock Joints
}

\author{
Buddhima Indraratna \\ PhD, FTSE, FIEAust, FASCE, FGS, FAusIMM, DIC
}

Professor of Civil Engineering and Research director, Centre for Geomechanics and Railway Engineering; Program Leader, ARC Centre of Excellence for Geotechnical Science and Engineering; University of Wollongong, Wollongong, NSW 2522, Australia. Email: indra@uow.edu.au

\section{Chandrasiri Kumara}

BSc (Hons) $1^{\text {st }}$ class, S.M.ASCE

$\mathrm{PhD}$ candidate, Centre for Geomechanics and Railway Engineering; University of Wollongong, Wollongong, NSW 2522, Australia. Email: ckw172@uowmail.edu.au

\section{Song-Ping Zhu}

$\mathrm{PhD}, \mathrm{MS}$ (Michigan)

Professor of Applied Mathematics; School of Mathematics and Applied Statistics University of Wollongong, Wollongong, NSW 2522, Australia. Email: spz@uow.edu.au

\section{Scott Sloan}

PhD (Cantab), CPEng, FIEAust, MASCE, FAA, FTSE

Laureate Professor of Civil Engineering ARC Centre of Excellence for Geotechnical Science and Engineering Civil, Surveying and Environmental Engineering, University of Newcastle Callaghan, NSW 2308, Australia. Email: scottwsloan@bigpond.com

\section{Author of correspondence:}

Prof. Buddhima Indraratna

Centre for Geomechanics and Railway Engineering,

Faculty of Engineering,

University of Wollongong,

Wollongong, NSW 2522

Australia

Ph: +61242213046

FAX: +61242213238

Email: indra@uow.edu.au

Submit to the International Journal of Geomechanics 


\section{Mathematical Modelling and Experimental Verification of Fluid Flow through Deformable Rough Rock Joints}

(1)

Buddhima Indraratna, F.ASCE ${ }^{1}$; Chandrasiri Kumara, S.M.ASCE ${ }^{2}$; Song-Ping Zhu ${ }^{3}$;

\author{
Scott Sloan, M.ASCE ${ }^{4}$
}

Rock joints exert an enormous influence on the permeability of a rock mass because they act as interconnecting networks that provide pathways for fluids to permeate and flow within its structure. The apertures in rock joints are irregular in nature and induce flows that cannot be described by the parallel plate theory based on planar joints or the classical cubic flow relationships. In this study, a two-dimensional hydraulic aperture distribution was considered to develop a mathematical model for fracture flow. In this approach, the threedimensional Navier-Stokes equation was integrated over the joint aperture and converted to an equivalent two-dimensional flow model. The proposed model was then solved numerically by adopting the SIMPLE (Semi Implicit Method for Pressure Linked Equations) algorithm for coupling the pressure and velocity and implementing it in MATLAB as a computer program. This program is capable of predicting the deformation of the joint apertures upon normal loading, the resulting flow patterns, and the volumetric flow rates associated with permeability tests conducted using the High Pressure Triaxial Apparatus which has been designed and built at the University of Wollongong. The model output for different

${ }^{1}$ Professor of Civil Engineering and Research director, Centre for Geomechanics and Railway Engineering; Program Leader, ARC Centre of Excellence for Geotechnical Science and Engineering; University of Wollongong, Wollongong, NSW 2522, Australia (corresponding author). Email: indra@uow.edu.au

$2 \mathrm{PhD}$ candidate, Centre for Geomechanics and Railway Engineering; University of Wollongong, Wollongong, NSW 2522, Australia.

${ }^{3}$ Professor of Applied Mathematics, School of Mathematics and Applied Statistics University of Wollongong, Wollongong, NSW 2522, Australia.

${ }^{4}$ Laureate Professor of Civil Engineering ARC Centre of Excellence for Geotechnical Science and Engineering Civil, Surveying and Environmental Engineering, University of Newcastle Callaghan, NSW 2308, Australia. 
20 conditions of confining stresses and hydraulic gradients was computed, and a good agreement

21 with the experimental results was observed.

22 Subject Headings: Rock mechanics, Fluid flow, Mathematical models, Two-dimensional 23 models, Flow simulation

24 Author Keywords: Fracture permeability, Fluid flow, Aperture distribution, Triaxial testing 
The permeability of jointed rock mass plays a major role in many industrial activities such as underground mining, petroleum extraction, ground water extraction, geothermal reservoirs, and underground nuclear repositories. The flow through a real rock fracture is a complex phenomenon due to the irregularity and alteration of its flow domain. The fracture aperture is spatially irregular and, according to the surrounding stress environment, its distribution can be changed. Investigations into the permeability of rock fractures began with the simplified assumption that two parallel plates would represent a planar joint (Lomize 1951; Baker 1955). This led to the development of the cubic formula shown in Eqn. which aims to predict the volumetric fluid flow by coupling the hydraulic and mechanical characteristics using Darcy's law (Snow 1968; Witherspoon et al. 1980)

$36 \quad Q=\frac{e^{3} w}{12 \mu} \frac{d P}{d x}$

where, $Q$ is the flow rate, $e$ is the fracture aperture, $w$ is the fracture width, $\mu$ is the dynamic viscosity, and $d P / d x$ is the total pressure gradient. When the flow through fractures is assumed to be Darcian, the intrinsic permeability coefficient of the rock fracture can be taken as $e^{2} / 12$ (Snow 1968). Subsequently, researchers such as Iwai (1976) and Gangi (1978) modified this coefficient of fracture permeability to account for the fracture irregularity and contacts, as well as the pressure distribution. For practical applications, flow through fractures has to be considered in rock fracture networks and the cubic formula, due to its simplicity, is often used for this purpose. When the rock matrix porosity is high so that its permeability is significant, dual porosity models have been developed for permeability calculations of fractured rock strata (Choi et al. 1997; Sarkar et al. 2004; Crandal et al. 2010; Kubeyev 2013). Wang et al. (2002) suggested a dual fracture model for calculating the permeability of a fracture network to overcome the complexity of joint sets. 
In the parallel plate model the advection and diffusion terms are dropped in favour of

50 one dimensional steady flow, where the pressure gradient is assumed to act in the flow direction only. However, in most cases, the flow does not follow the conventional form of

Darcy's law and the reasons for this have been investigated extensively (Witherspoon et al. 1980; Zimmerman and Bodvarsson 1996; Zimmerman et al. 2004). Barton et al. (1985) suggested using an empirical relationship to calculate the hydraulic aperture with the Joint Roughness Coefficient (JRC) of the rock surface, while Neuzil and Tracy (1981) suggested a fractal model to account for the aperture irregularity. Zimmerman et al. (1992) demonstrated numerically the permeability variations due to the presence of contacts in different shapes and quantities, and quantified the effective permeability of a fracture with contact areas. Ranjith and Viete (2011) discussed the applicability of the cubic law for non-Darcian flows and suggested the cubic law is still applicable for flows with a Forcheimer number less than 1.3. Singh et al (2014) used an analogue material to simulate the roughness of the fractures subjected to water flow.

Two-dimensional flow models (2D) flow models (Fig. 1). First, the flow domain can be viewed from a side parallel to the flow direction (Koyama 2007; Zimmerman and Yeo 2013). Alternatively the flow modelling can be based on the plan view of the fracture (Bear 1993; Kishida et al. 2013). In the former, the aperture height is in the direction of the vertical dimension and, therefore, the aperture variation can be incorporated directly into the flow model. However, these models account for the variation of the aperture in one plane only, which is parallel to the flow direction. The variation of aperture lateral to the flow direction is not discussed, and at the same time the lateral velocity component perpendicular to the main flow direction is not included in the flow equations, while the vertical velocity component is included. The latter approach can be 
used to define the spatial distribution of flow in a $2 \mathrm{D}$ fracture. The velocity in the direction perpendicular to the plane of the aperture is assumed to be negligible, compared to the flow that occurs in the lateral and longitudinal directions of the fracture.

Amadei \& Illangasekare (1992) derived a 2D analytical model by assuming one directional flow for steady or transient flows. Here the aperture was not one separate value and the user was able to measure the apertures in preferred intervals and then calculate the associated flow behaviour. Indraratna et al. (2002) and Price and Indraratna (2005) suggested the use of Fourier analysis to describe the irregularity of the fracture aperture. Fourier coefficients were calculated using the scanned joint surfaces, and the variations of the fracture aperture were obtained as Fourier functions. Zimmerman and Yeo (2013) used a 2D rock fracture viewed from a side of the fracture and proved that the Navier-Stokes equation can be linearized into the Stokes equation, by neglecting the advection acceleration terms compared to the viscous terms, provided the Reynolds number of the flow is less than about 10. Koyama (2007) modelled flow and particle transport in rock fractures during shear by looking at the fracture from one side using the Reynolds equation. Here the Navier-Stokes equations were solved using commercial software and the simulations were compared with laboratory shear-flow-tracer tests to demonstrate that the Reynolds equation overpredicts the flow rate by roughly $5-10 \%$ compared to the Navier-Stokes analysis. Zimmerman et al. (2004) conducted laboratory measurements and Navier-Stokes simulations on fracture flow to study the non-linear regimes of fracture flow. They discovered that there is a weak inertia regime within the Reynolds number range 1-10, and the influence is significantly less for the Forchheimer type regime beyond a Reynolds number of 20.

In contrast to 2D models where the fracture is viewed from a side, Bear (1993) modelled the flow in a non-deforming fracture through the plan view by integrating the threedimensional Navier-Stokes equation in the direction of the aperture height. Kishida et al. 
99

100

101

$$
\frac{\partial(\rho \bar{V})}{\partial t}+\nabla \bullet(\rho \bar{V} \bar{V})+\nabla p-\rho g \nabla Z^{\prime}-\nabla \bullet \bar{T}=0
$$

115 where $\bar{V}$ is the velocity vector, $\rho$ is the fluid density, $p$ is the fluid pressure, $g$ is the acceleration due

116 to gravity, $\overline{\bar{T}}$ is the stress tensor given by $\overline{\bar{T}}=\mu\left[\nabla \bar{V}+(\nabla \bar{V})^{T}-2 / 3(\nabla \bullet \bar{V}) \overline{\bar{I}}\right], \overline{\bar{I}}$ is the unit tensor,

117 and $\mu$ is the dynamic viscosity of the fluid. Assuming the fluid is a homogeneous and Newtonian 118 incompressible liquid, Eqn. (2) can be expressed as follows (Bear 1993)

119 
121 integrating Eqn. (3) in the direction of the height of the aperture, or the $z$ direction in Fig. 2, to obtain a $2 \mathrm{D}$ flow model where the plan view of the fracture is considered. In order to model water flow through deformable rock fractures, the limits of the integration can be

124 considered to be functions of time, thus yielding a two dimensional depth-averaged 125 momentum conservation equation in the $(x, y)$ space as:

$126 \int_{F_{l}}^{F_{u}}\left(\frac{\partial(\rho \bar{V})}{\partial t}+\nabla \bullet(\rho \bar{V} \bar{V})+\nabla p-\rho g \nabla Z^{\prime}-\mu \nabla^{2} \bar{V}\right) d z=0$

127 Integration of this expression by parts using the Leibnitz integral theorem (Appendix A), 128 leads to:

130 where

$131 \quad \bar{V}=\frac{1}{e} \int_{F_{l}}^{F_{u}} \bar{V} d z$

132 In the above $\overline{\dot{V}}$ is the averaged velocity vector in the $(x, y)$ plane, and $\dot{\nabla}$ denotes the corresponding divergence operator. Note that a parabolic distribution of velocities in the

134 vertical direction was assumed in the integration process. The continuity equation for flow is 135 given by Eqn. (7) as follows:

$136 \frac{\partial \rho}{\partial t}+\nabla \bullet(\rho \bar{V})=0$

137 Integrating Eqn. (7) in the same manner as before gives the depth-averaged continuity equation for an incompressible fluid in two dimensions as: 
$139 \dot{\nabla} \bullet(\rho e \overline{\dot{V}})=0$

\section{Deformation Criteria}

The fracture aperture deformation $D_{n}$ is controlled by the mechanical deformation of the joint. According to Kulhawy (1975) and Bandis et al. (1983), the deformation of the joint and the effective normal stress have a hyperbolic relationship which is given by Eqn. (9):

$144 \quad D_{n(t)}=\frac{\sigma_{n}^{\prime} D_{n m}}{\sigma_{n}^{\prime}+K_{i} D_{n m}}$

where, $\sigma_{n}^{\prime}$ is the effective normal stress, $D_{n m}$ is the maximum deformation of the fracture

146 (which is always less than the fracture aperture), $K_{i}$ is the initial joint normal stiffness when the applied effective stress is zero, and $D_{n(t)}$ is the total deformation for a particular applied normal stress. The deformation measured upon initial loading during the test is used to calculate the initial joint normal stiffness by re-arranging Eqn. (9) into Eqn. (10). A correction is applied for the deformation of the membrane that added to the fracture aperture deformation readings (Zhang 2013). Coupling the deformation criteria to the flow model is described in the next section.

$\frac{1}{D_{n(t)}}=K_{i} \frac{1}{\sigma_{n}^{\prime}}+\frac{1}{D_{n m}}$ cannot be solved analytically for transient or steady state flows because the pressure is linked with velocity and there is no separate equation to calculate the pressure. Therefore, a numerical solution method is required to solve Eqns. (5) and (8), and it can be obtained as described below. 
The scalar form of Eqn. (5) for steady flow is shown in Eqns. (11) and (12) . For relatively low flow velocities through rock fractures, the advection acceleration terms are small compared to the viscous terms (Koyama 2007; Zimmerman and Yeo 2013; Kishida et al. 2013). Therefore they are neglected for simplicity and the equations are discretised using the Finite Volume Method (Versteeg and Malalasekara 2007) and solved by the SIMPLE algorithm (Patanker and Spalding 1972). Scalar velocity components $(u, v)$ are depth averaged values and the superscript 'dot' is not used as in the vector equation for simplicity.

$\mu \frac{\partial^{2}}{\partial x^{2}}(e u)+\mu \frac{\partial^{2}}{\partial y^{2}}(e u)-\frac{12 \mu u}{e}+\rho g e \frac{\partial Z^{\prime}}{\partial x}-e \frac{\partial p}{\partial x}=0$

$\mu \frac{\partial^{2}}{\partial x^{2}}(e v)+\mu \frac{\partial^{2}}{\partial y^{2}}(e v)-\frac{12 \mu v}{e}+\rho g e \frac{\partial Z^{\prime}}{\partial y}-e \frac{\partial p}{\partial y}=0$

The flow domain is discretised as a structured mesh that is shown in Fig. 2 as continuous lines. The $x$-axis is numbered in capital ' $I$ 's and the $y$-axis in capital ' $J$ 's. The grid nodes are the centres of the control volumes, and the scalar variables of the cell, such as pressure, hydraulic aperture and density, are kept at the cell centre. The two velocity components ' $u$ ' and ' $v$ ' are kept at the faces of the cell, as shown. A staggered grid was created in order to have the grid lines on the centres of the scalar cell faces, which are numbered using ' $i$ 's on the $x$-axis and ' $j$ 's in the $y$-axis. The ' $u$ ' and ' $v$ ' velocities of a particular cell, say $(I, J)$ are denoted as $u_{i, J}$ and $v_{I, j}$ respectively. A control volume (cell) for flow calculations and a cell for the ' $u$ ' velocity and a cell for the ' $v$ ' velocity are shown in Fig. 2.

Eqns. (11) and (12) can be integrated over a control volume for $u$ and $v$ respectively, and the discretised equations, adopting the central difference scheme, are as follows: 
182

$e_{i, J}\left[-\frac{2 \mu}{\Delta x^{2}}-\frac{2 \mu}{\Delta y^{2}}-\frac{12 \mu}{e_{i, J}^{2}}\right] u_{i, J}^{\#}+\left[\frac{e_{i-1, J} \mu}{\Delta x^{2}}\right] u_{i-1, J}^{\#}+\left[\frac{e_{i+1, J} \mu}{\Delta x^{2}}\right] u_{i+1, J}^{\#}$

$+\left[\frac{e_{i, J-1} \mu}{\Delta y^{2}}\right] u_{i, J-1}^{\#}+\left[\frac{e_{i, J+1} \mu}{\Delta y^{2}}\right] u_{i, J+1}^{\#}=\varphi_{i, J}$

183

$e_{I, j}\left[-\frac{2 \mu}{\Delta x^{2}}-\frac{2 \mu}{\Delta y^{2}}-\frac{12 \mu}{e_{I, j}^{2}}\right] v_{I, j}^{\#}+\left[\frac{e_{I-1, j} \mu}{\Delta x^{2}}\right] v_{I-1, j}^{\#}+\left[\frac{e_{I+1, j} \mu}{\Delta x^{2}}\right] v_{I+1, j}^{\#}$

$+\left[\frac{e_{I, j-1} \mu}{\Delta y^{2}}\right] v_{I, j-1}^{\#}+\left[\frac{e_{I, j+1} \mu}{\Delta y^{2}}\right] v_{I, j+1}^{\#}=\varphi_{I, j}$

where

185

$\varphi_{i, J}=-(\rho g e)_{i, J} \frac{\Delta Z^{\prime}}{\Delta x}+\left(e_{i, j} \frac{p_{I+1, J}^{\#}-p_{I-1, J}^{\#}}{\Delta x}\right)$ and $\varphi_{I, j}=-(\rho g e)_{I, j} \frac{\Delta Z^{\prime}}{\Delta y}+\left(e_{I, j} \frac{p_{I, J+1}^{\#}-p_{I, J-1}^{\#}}{\Delta y}\right)$

The relations for the gravity and pressure were solved explicitly, together with the

pressure, and the quantities $\varphi_{i, J}, \varphi_{I, j}$ contain those terms. The terms with the superscript '\#'

are the solutions of the equations for intermediate velocities and need to be corrected to

satisfy the continuity of flow. In the SIMPLE algorithm, these intermediate velocities were

treated as the difference between the final velocity and the velocity corrections. The

191 intermediate pressure was also treated as the difference between the final pressure and the pressure correction. Thereafter, a relationship for the ' $u$ ' component velocity corrections $\left(u^{\prime}\right)$ and pressure correction $\left(p^{\prime}\right)$ was obtained (Appendix B) as shown in Eqn. (15). A similar equation can be obtained for the velocity correction $\left(v^{\prime}\right)$ following the same procedure.

195

$$
\begin{aligned}
& e_{i, J}\left[-\frac{2 \mu}{\Delta x^{2}}-\frac{2 \mu}{\Delta y^{2}}-\frac{12 \mu}{e_{i, J}^{2}}\right] u_{i, J}^{\prime}+\left[\frac{e_{i-1, J} \mu}{\Delta x^{2}}\right] u_{i-1, J}^{\prime}+\left[\frac{e_{i+1, J} \mu}{\Delta x^{2}}\right] u_{i+1, J}^{\prime} \\
& +\left[\frac{e_{i, J-1} \mu}{\Delta y^{2}}\right] u_{i J-1}^{\prime}+\left[\frac{e_{i, J+1} \mu}{\Delta y^{2}}\right] u_{i, J+1}^{\prime}=e_{i, j} \frac{p_{I+1, J}^{\prime}-p_{I-1, J}^{\prime}}{\Delta x}
\end{aligned}
$$


the iteration process. Since these corrections ultimately become negligible, this omission does not affect the solution itself but does influence the speed of convergence. After the omission of neighbour cell velocity corrections, the Eqn. (15) becomes Eqn. (16) and the Eqn. (17) is obtained following the same procedure for the velocity component ' $v$ '.

201

$$
u_{i, J}^{\prime}=\frac{1}{\left[-\frac{2 \mu}{\Delta x^{2}}-\frac{2 \mu}{\Delta y^{2}}-\frac{12 \mu}{e_{i, J}^{2}}\right]}\left(\frac{p_{I+1, J}^{\prime}-p_{I-1, J}^{\prime}}{\Delta x}\right)
$$

202

$$
v_{I, j}^{\prime}=\frac{1}{\left[-\frac{2 \mu}{\Delta x^{2}}-\frac{2 \mu}{\Delta y^{2}}-\frac{12 \mu}{e_{I, j}{ }^{2}}\right]}\left(\frac{p_{I, J+1}^{\prime}-p_{I, J-1}^{\prime}}{\Delta y}\right)
$$

In Eqns. (16) and (17), the terms with a dash denote the corrections. Since the intermediate velocities and their corresponding corrections are known, the final velocities can be obtained. equation (Poisson type) is obtained (Appendix B), as shown in Eqn. (18).

207

$$
M_{I, J} p_{I, J}^{\prime}+M_{i, J} p_{I+1, J}^{\prime}+M_{i-1, J} p_{I-1, J}^{\prime}+M_{I, j} p_{I, J+1}^{\prime}+M_{I, j-1} p_{I, J-1}^{\prime}=\frac{\left(\rho e u^{\#}\right)_{i, J}}{\Delta x}
$$

$$
-\frac{\left(\rho e u^{\#}\right)_{i-1, J}}{\Delta x}+\frac{\left(\rho e v^{\#}\right)_{I, j}}{\Delta y}-\frac{\left(\rho e v^{\#}\right)_{I, j-1}}{\Delta y}
$$

where, $M_{I, J}=-M_{i, J}-M_{i-1, J}-M_{I, j}-M_{I, j-1}, M_{i, J}=-\frac{\rho e_{i, J}}{H_{i, J} \Delta x^{2}}, M_{i-1, J}=-\frac{\rho e_{i-1, J}}{H_{i-1, J} \Delta x^{2}}$,

$$
M_{I, j}=-\frac{\rho e_{I, j}}{H_{I, j} \Delta y^{2}}, M_{I, j-1}=-\frac{\rho e_{I, j-1}}{H_{I, j-1} \Delta y^{2}}, \text { and } H_{i, J}=-\frac{2 \mu}{\Delta x^{2}}-\frac{2 \mu}{\Delta y^{2}}-\frac{12 \mu}{e_{i, J}^{2}} \text {. }
$$

210 The intermediate velocities obtained by solving Eqns. (13) and (14) can be substituted in Eqn.

211 (18) to find the pressure corrections, which are then inserted into Eqns. (16) and (17) to 
212 determine the velocity corrections. If the corrections are significant, the new pressure is taken

213 as the intermediate pressure, and the same procedure is repeated until all the corrections 214 become negligible. The model contains the fracture aperture as a variable in 2D space and 215 time which differentiates the model from the usual Navier-Stokes equation. The complete 216 SIMPLE algorithm is shown in Fig. 4. around the contacts. According to the hyperbolic relationship, an aperture is fully closed when the applied stress is at infinity. However, compared to larger apertures in the domain, the small apertures reach closure earlier. Eqn. (9) was used to calculate the normal deformation of a fracture considering a maximum closure for the domain. Bandis et al. (1983) suggested empirical relations to obtain the maximum closure using the usual parameters such as the joint roughness coefficient (JRC), the joint compressive strength (JCS) and some material constants. In this study, the apertures of the domain are treated individually, and therefore, each aperture is given a unique maximum closure. Then Eqn. (9) can be given in the discretized format as follows:

$$
D_{n(t)[I, J]}=\frac{\sigma_{n[I, J]}^{\prime} D_{n m[I, J]}}{\sigma_{n[I, J]}^{\prime}+K_{i} D_{n m[I, J]}}
$$

The above approach allows the initially smaller apertures to reach closure upon the application of stress while the larger apertures still conduct flow. The initial aperture at zero confining stress was taken as the maximum closure and the initial joint normal stiffness was taken as a constant for all apertures. The coupling of deformation into the flow calculation is 232 shown in Fig. 4. 


\section{Boundary Conditions}

Constant pressure boundary conditions were applied at the inlet and outlet, and the

237 inlet pressure was the applied back pressure and the outlet pressure was maintained at zero.

238 No slip velocity boundaries were assumed at the fracture walls in the model derivation and,

239 therefore, the velocities at the wall boundaries are zero. The longitudinal wall boundaries, or

240 the membrane, were assumed to be walls with zero velocity and a zero pressure gradient

241 normal to the wall. The inlet and outlet boundary velocities were calculated along with the

242 domain velocities.

\section{MATLAB Computational Program}

Although the model proposed is two-dimensional, standard 2D Navier-Stokes solvers cannot be used to furnish the solution. Thus, it was necessary to implement a new solution scheme using MATLAB. The resulting program consists of graphical user interfaces (GUI) for the user inputs, and solution outputs that are connected to MATLAB functions. The user can select the relaxation factors and the accuracy required for the convergence criteria. The key inputs for the program are a matrix containing the initial fracture aperture distribution over the flow domain and other parameters such as the initial joint normal stiffness and the fluid properties. The method for obtaining the initial fracture aperture is discussed later under the experimental procedure. The fracture dimensions are given and, the domain is discretised by the program according to the user's preferences. The user can activate a confining stress increment and obtain the corresponding flow rate and aperture changes for desired confining stress increment levels. The resulting flow vectors are displayed as arrows with flow directions and relative magnitudes. The background of the plot is either the aperture distribution or a pressure distribution contour map. The outlet flow rate is calculated as the summation of the flow rates of the cell array at the outlet, according to: 
$259 \quad Q=\sum_{k=1}^{m}\left[u_{n k} e_{n k} \Delta y\right]$

260 In the above, $m$ is the number of grids in the $y$-direction and $n$ is the outlet boundary grid

261 number in the $x$-direction. The aperture deformation and flow rate are displayed graphically

262 at the end of each calculation.

The solution domain contained 6156 scalar cells with a $1 \mathrm{~mm}$ grid spacing. The convergence of the solution was examined for a flow rate with a coarser grid spacing of 2 $\mathrm{mm}$, and up to relatively fine grid spacing of $0.4 \mathrm{~mm}$. A grid spacing of $1 \mathrm{~mm}$ was found to converge efficiently and was selected for the analyses. New velocities and pressures were updated at each cycle iteratively, using a relaxation factor of 0.5 .

\section{Experimental Procedure}

Permeability tests were carried out using the high pressure two-phase triaxial apparatus (HPTPTA) (Indraratna and Haque 1999) to compare with the model predictions. Rock specimen of $54 \mathrm{~mm}$ diameter with a sub-axial tension crack was used for the tests. The specimen was enclosed in a polyurethane membrane and two cantilever arms were used to measure the deformations of the fracture (Fig. 5). The confining pressure was applied using silicone oil, which does not react with the membrane, and the outlet fluid was collected on an electronic balance to measure the flow rate. A schematic diagram of the test set up is shown in Fig. 6. The sandstone specimen was $114 \mathrm{~mm}$ high, and it was tested under 5 confining pressure levels (750kPa, $1 \mathrm{MPa}, 1.25 \mathrm{Mpa}, 1.5 \mathrm{MPa}$, and $1.75 \mathrm{MPa}$ ) ) and three levels of inlet pressure $(40 \mathrm{kPa}, 60 \mathrm{kPa}$ and $80 \mathrm{kPa})$. Once the flow became steady, the weight of outflow water was recorded in 15 second intervals for each combination of confining pressure and inlet pressure, while the confining pressure, inlet and outlet pressures, and fracture deformation were simultaneously recorded in a data taker. 

scanner before and after the test. The initial aperture distribution was measured using a silicon rubber solution. The solution was inserted into the fracture, without any pressure being applied to the fracture, and then allowed to set. Once set, the top half of the test specimen was carefully removed and the silicon rubber surface was scanned (Fig. 7). The silicon rubber was then removed from the lower half of the rock specimen and the surface of the lower half was scanned with respect to the same reference point in order to obtain the surface coordinates of both surfaces with the same origin. The difference between the two surface coordinates was then taken as the fracture aperture distribution. The steps of the scanning procedure are illustrated in Fig. 8 (Price and Indraratna 2005).

\section{Results and Discussion}

Fig. 9 shows the flow vectors and aperture contours obtained for the fractured sandstone specimen at an inlet pressure of $40 \mathrm{kPa}$. Fig. 9 shows the velocity and aperture distributions at confining pressures of $750 \mathrm{kPa}, 1000 \mathrm{kPa}$, and $1750 \mathrm{kPa}$, respectively. The contour maps indicate the aperture deformation at increasing confining pressure in successive plots, while the velocity vectors represent the flow paths for which the size of the arrow is proportional to the magnitude. The smallest apertures with no significant velocity are the contacts of the domain. Fig. 10 shows the flow vectors, as well the pressure contours in the background, for the test subjected to an inlet pressure of $40 \mathrm{kPa}$ and a confining pressure of $1000 \mathrm{kPa}$. Initially, a uniform pressure distribution (i.e. equal pressure lines are vertical and parallel) was prescribed according to the inlet and outlet pressures. However, for the same aperture distribution shown in Fig. 9(b), when the mathematical model is solved, Fig. 10 verifies that the fluid pressure is not uniformly distributed for irregular apertures. For smaller 
$313 \quad \operatorname{Re}=\frac{\bar{e} U \rho}{\mu}$

accompanied by an increased flow velocity. In contrast, for larger apertures, the fluid pressure becomes lower with a correspondingly reduced flow velocity.

Fig. 11 shows the model predictions and laboratory test data for the volumetric flow rate against confining stress together with the corresponding Reynolds number. It illustrates the variation of the Reynolds number (Re) with the confining pressure at three different inlet pressures based on Eqn. (21), where the average aperture $(\bar{e})$ can be used as the characteristic linear dimension (Kishida et al. 2013; Singh et al. 2014), thus:

In the above, $U$ is the mean velocity, $\rho$ is the fluid density and $\mu$ is the dynamic fluid viscosity. The model predictions are in good agreement with the laboratory data and they validate the proposed approach. Due to the omission of inertia terms in the solution procedure, the relatively high flow rates observed at confining pressures less than $1000 \mathrm{kPa}$ for a corresponding Reynolds number exceeding 10, show a noticeable deviation from the experimental results. Since the model uses the variation of the aperture in space, the effect of the uneven flow path is addressed more explicitly. The model is proposed for underground flow calculations to predict the rock permeability at different depths. Conventional triaxial permeability tests suffer from obvious limitations and practical difficulties. For example, the sample size is considerably smaller and the use of a membrane can introduce boundary effects. Preparing specimens is a challenging task when the rock samples have to be cored with a sub axial fracture. Usually a fracture is induced in a real rock specimen in the laboratory, but identical fracture patterns cannot be guaranteed for conducting multiple tests to improve the reliability of the test data. An aperture distribution can be obtained from a sample with any shape, and a sub-sample of rectangular cross section can be processed and used for the model calculations. The membrane boundary effect can be negated by 
considering the side boundaries as symmetrical. In this manner, the permeability in both the longitudinal and lateral directions can be obtained which is often infeasible in conventional triaxial testing.

The evolution of fracture flow during shearing of rock fractures has been researched widely (Yeo et al. 1998; Koyama 2007). Rock fracture shearing affects the flow as the fracture walls dilate or compress while shearing. However, actual shearing rates are very small compared to the fluid flow rates, so in the case of predicting flow rates in underground openings or petroleum extraction in the short term, the role of fracture shearing becomes marginal. On the other hand, the fracture shearing is essential for accurately calculating flow rates through fractures over a long period of time. The proposed model is capable of predicting the flow rates given the aperture distribution in local 2D space. The model is coupled with the normal deformation under normal load in order to predict the aperture distribution at different depths, noting that the applied normal stress increases with depth. The model can also be coupled with a shear-dilation model to predict the aperture evolution chronologically and predict the flow rates accordingly.

\section{Conclusion}

In this paper, the formulation of a mathematical model and a numerical solution scheme based on MATLAB were presented to determine the velocity and pressure distributions in 2D space for fluid flow through a rough, deformable rock fracture. A MATLAB program incorporating the Authors' model was employed to simulate the triaxial single fracture permeability test, in which the main controlling parameters included the initial aperture distribution, the fracture dimensions, the initial joint normal stiffness, the fluid density, the dynamic fluid viscosity, the number of grids in the ' $\mathrm{X}$ ' and ' $\mathrm{Y}$ ' directions of the fracture, and the increments of applied confining pressure. In summary, for a computed 
aperture deformation, the program calculates and illustrates graphically the velocity and pressure distributions and the velocity vector plots.

Rock fracture permeability tests were conducted using the High pressure Two-Phase Triaxial Apparatus (HPTPTA) to validate the model. With an acceptable margin of error, the overall model predictions were generally in good agreement with the laboratory results. One of the main reasons for proposing this new model for real rock fracture flows was to demonstrate the changes in the flow due to aperture changes with the applied stress, and to quantify the flow behaviour with increasing confining pressure. Both the model predictions and the experimental results indicate that the relationship between the fracture permeability and the applied normal stress can be represented by a power function.

Unlike most 2D models, a salient feature of the proposed mathematical model is that the joint aperture is not assumed to be constant. In fact, the stress-deformation response of the aperture is fully coupled with the flow equations, thus the magnitude of flow is not only influenced by the effective stress, but also by the changing aperture simultaneously. Subsequently, the overall flow at any time at the outlet is determined by integrating the flow components of the cell array.

The inertia terms of the mathematical model were neglected in the numerical formulation because of the relatively slow fluid flows and for the convenience of eliminating the difficulties attributed to non-linearity. Therefore, the current model calculations are only realistic for slow flow velocities through rock fractures at a Reynolds number less than 10 . In this study, the fracture was assumed to be planar with rough fracture walls, thus the model is not expected to be accurate for non-planar discontinuities such as folds. Another limitation of the model is that it considers steady state flows only. Although modification of the model to include transient flows is currently being studied, it is not within the scope of this paper. 
378 In spite of these limitations, the proposed mathematical model provides a rational tool to 379 predict flow through a fracture in lieu of conventional laboratory permeability testing.

380 Acknowledgement

The authors acknowledge the Australian Research Council (ARC) for funding the research project. Dr. Jan Nemcik of University of Wollongong and Dr. Winton Gale of SCT Pty Ltd are acknowledged for the support given at various times in the project. The authors wish to acknowledge $\mathrm{Mr}$ Alan Grant and the Engineering faculty technical staff of the University of Wollongong for their efforts on the laboratory experiments. The second author support.

\section{References}

Amadei, B., and Illangasekare, T. (1992). "Analytical solutions for steady and transient flow in nonhomogeneous and anisotropic rock joints." Int. J. rock. Mech. Min. Sci. \& Geomech. Abstr. 29(6): 561-572.

Barton, N., Bandis, S., and Bakhtar, K. (1985). "Strength, Deformation and Conductivity Coupling of Rock Joints." Int. J. Rock Mech. Min. Sci. 22(3): 121-140.

Bear, J., Tsang, C. F., and de Marsily, G. (1993). "Flow and contaminant transport in fractured rock", Academic Press, California. 
Choi, E. S., Cheema, T., and Islam, M. R. (1997). "A new dual-porosity/dual-permeability model with non-Darcian flow through fractures." J. Petroleum Sci. Eng. 17(3-4): 331-344.

Crandall, D., Ahmadi, G., and Smith, D. (2010). "Computational Modeling of Fluid Flow through a Fracture in Permeable Rock." Transp. Porous Media 84(2): 493-510.

Gangi, A. F. (1978). "Variation of whole and Fractured Porous Rock Permeability with Confining Pressure." Int. J. Rock Mech. Min. Sci. Geomech. Abstr. 15: 249-257.

Indraratna, B., and Haque, A. (1999). "Triaxial equipment for measuring the permeability and strength of intact and fractured rocks." Geotechnique 49(4): 515-521.

Indraratna, B., Price, J., and Gale, J. (2002). "Fourier description of fracture roughness". 5th North American Rock Mechs Symp., University of Torronto Press, Torronto, 35-44

Iwai, L. (1976). "Fundamental studies of fluid flow through a single fracture". University of California, Berkerley, PhD: 208.

Kishida, K., Sawada, A., Yasuhara, H., and Hosoda, T. (2013). "Estimation of fracture flow considering the inhomogeneous structure of single rock fractures." Soils and Foundations 53(1): 105-116.

Koyama, T. (2007). "Stress, Flow and Particle Transport in Rock Fractures". Department of Land and Water Resources Engineering, Royal Institute of Technology (KTH), Stockholm, PhD: 289.

Kubeyev, A. (2013). "Impact of multi-set fracture pattern on the effective permeability of fractured porous media." J. Petroleum Sci. and Eng. 112: 161-169.

Kulhawy, F. H. (1975). "Stress deformation properties of rock and rock discontinuities." Engineering Geology 9(4): 327-350.

Lomize, G. M. (1951). "Flow in Fractured Rocks (English Translation) ". Gosenergoizdat, State Press

Neuzil, C. E., and Tracy, J. V. (1981). "Flow through fractures." Water Resour. Res. 17(1): 191-199. 
Patanker, S. V., and Spalding, D. B. (1972). "A calculation procedure for heat, mass and momentum transfer in three-dimensional parabolic flows." Journal of Heat and Mass Transfer 15(10): 17871806.

Price, J., and Indraratna, B. (2005). "Development of an equivalent homogenous fluid model for pseudo-two-phase (air + water) flow through fractured rock." J. Geotech. Geoenviron. Eng. 131(7): 857-866.

Ranjith, P. G., and Viete, D. R. (2011). "Applicability of the 'cubic law' for non-Darcian fracture flow." J. Petroleum Sci. and Eng. 78(2): 321-327.

Sarkar, S., Toksoz, M. N., and Burns, D. R. (2004). "Fluid Flow Modelling in Fractures". Earth Resources Laboratory Industry Consortia Annual Report, Massachusetts Institute of Technology, Cambridge.

Singh, K., Singh, D., and Ranjith, P. (2014). "Simulating Flow through Fractures in a Rock Mass Using Analog Material." Int. J. Geomech. 14(1): 8-19.

Snow, D. T. (1968). "Rock fracture spacings, openingsand porosities." Soil Mech. Found. Div. ASCE 94(SMI): 73-91.

Versteeg, H. K., and Malalasekara, W. (2007). "An introduction to computational fluid dynamics". Pearson Education Ltd, Harlow.

Wang, E. Z., Yue, Z. Q., Tham, L. G., Tsui, Y., and Wang, H. T. (2002). "A dual fracture model to simulate large-scale flow through fractured rocks." Canadian geotechnical journal 39(6): 13021312.

Witherspoon, P. A., Wang, J. S. Y., Iwai, K., and Gale, J. E. (1980). "Validity of Cubic Law for Fluid Flow in a Deformable Rock Fracture." Water Resour. Res. 16(6): 1016-1024.

Yeo, I. W., de Freitas, M. H., and Zimmerman, R. W. (1998). "Effect of shear displacement on the aperture and permeability of a rock fracture." Int. J. Rock Mech. Min. Sci. 35(8): 1051-1070. 
Zhang, Z. (2013). "Hydromechanical behaviour and nonlinear flow characteristics of rock fractures". School of Civil, Mining and Environmental Engineering, University of Wollongong, Wollongong, PhD: 215.

Zimmerman, R. W., Al-Yaarubi, A., Pain, C. C., and Grattoni, C. A. (2004). "Non-linear regimes of fluid flow in rock fractures." Int. J. Rock Mech. Min. Sci. 41: 163-169.

Zimmerman, R. W. and Bodvarsson, G. S. (1996). "Hydraulic conductivity of rock fractures." Transp. Porous Media 23(1): 1-30.

Zimmerman, R. W., Chen, D.W., and Cook, N. G. W. (1992). "The effect of contact area on the permeability of fractures." Journal of Hydrology 139(1-4): 79-96.

Zimmerman, R. W., and Yeo, I.-W. (2013). "Fluid Flow in Rock Fractures: From the Navier-Stokes Equations to the Cubic Law”. Dynamics of Fluids in Fractured Rocks, B. Faybishenko, P. A. Witherspoon, and S. M. Benson, eds.,Vol. 122, American Geophysical Union, Washington, DC: 213-224. 


\section{Appendix: A}

461 Integrating the first term in Eqn. (4) by applying Leibniz's rule gives

$462 \quad \int_{F_{b}}^{F_{t}} \frac{\partial(\rho \bar{V}}{\partial t}=\frac{\partial}{\partial t} \int_{F_{b}}^{F_{t}}(\rho \bar{V}) d z+\left.\frac{\partial F_{b}}{\partial t} \rho \bar{V}\right|_{f_{s}}-\left.\frac{\partial F_{t}}{\partial t} \rho \bar{V}\right|_{f_{t}}$

463 Here $F_{b}=z_{b}+f_{b}$ anf $F_{t}=z_{t}+f_{t}$ where $z_{b}$ and $z_{t}$ are the $z$ coordinates of the bottom wall and top 464 wall profile for a particular point in $(x, y)$ space given by $f_{b}$ and $f_{t}$, respectively. Once no-slip 465 boundary conditions are assumed at the top and bottom surfaces, the last two parts of Eqn. 466 (A1) vanish. The density of the fluid is constant over the $z$ direction and Eqn. (A1) is reduced 467 to

$468 \quad \int_{F_{b}}^{F_{t}} \frac{\partial(\rho \bar{V}}{\partial t}=\frac{\partial}{\partial t}(\rho e \overline{\dot{V}})$

469 where

$470 \quad \bar{V}(x, y, z, t)=\overline{\dot{V}}(x, y, t)+\overline{\widetilde{V}}(x, y, z, t)$

471 The second term of the Eqn. (4) may be integrated using the same method. Assuming no-slip

472 boundary conditions at the walls and using Eqn. (A3), where $\overline{\tilde{V}}$ is the difference between the 473 velocity and the depth-averaged velocity, leads to

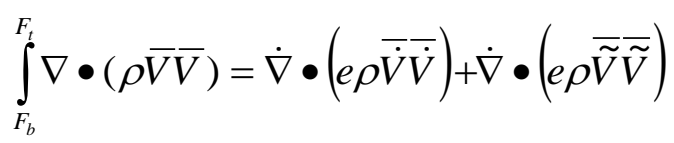

475 The last term of the above equation is the dispersive momentum flux and can be neglected 476 according to Bear (1993). Integrating the fifth term of the Eqn. (4) assuming the same conditions furnishes 
$478 \quad \int_{F_{b}}^{F_{t}} \mu \nabla^{2} \bar{V} d z=\mu \dot{\nabla}^{2} \bullet(e \overline{\dot{V}})+\mu\left\{\left.\nabla F_{b} \bullet \nabla \bar{V}\right|_{f_{b}}-\left.\nabla F_{t} \bullet \nabla \bar{V}\right|_{f_{t}}\right\}$

479 The last component of this equation can be reduced to $(12 \mu \bar{V} / e)$ by assuming non-shearing 480 walls and a parabolic distribution of velocity inside the fracture at the fully developed stage 481 of the flow. The remaining pressure and gravity terms in Eqn. (4) can be evaluated simply 482 and lead to Eqn. (5). 


\section{Appendix: B}

484

If the corrected velocity is $u$, intermediate velocity is $u^{\#}$ and the correction to be

485 applied to the intermediate velocity is $u^{\prime}$, then

486

$u=u^{\#}+u^{\prime}$

487 Similarly, for the pressures

488

$p+p^{\#}+p^{\prime}$

489 Substituting Eqns. (B1) and (B2) into Eqn. (13) and subtracting the resulting equation from

490 Eqn. (13) furnishes Eqn. (15).

491

In order to obtain the pressure equation, Eqn. (16) is substituted into Eqn. (B1) which

492 gives:

493

$u=u^{\#}+\frac{1}{\left[-\frac{2 \mu}{\Delta x^{2}}-\frac{2 \mu}{\Delta y^{2}}-\frac{12 \mu}{e_{i, J}^{2}}\right]}\left(\frac{p_{I+1, J}^{\prime}-p_{I-1, J}^{\prime}}{\Delta x}\right)$

494

A similar equation can be obtained for the $v$-velocity by following the same method,

495 and then those two equations can be used to define the neighbouring velocities of $u$

$496\left(u_{i, J}, u_{i-1, J}\right)$ and $v\left(v_{I, j}, v_{I, j-1}\right)$. Thereafter substituting these four equations in the discretised

497 continuity equation (Eqn. B4) gives the pressure equation (Eqn. 18).

$498 \frac{\left\lfloor(\rho e u)_{i, J}-(\rho e u)_{i-1, J}\right\rfloor}{\Delta x}+\frac{\left\lfloor(\rho e v)_{I, j}-(\rho e v)_{I, j-1}\right\rfloor}{\Delta x}=0$ 


\section{Notation}

$500 \quad \bar{V} \quad$ Velocity vector in 3D $(x, y, z)$

$501 \quad \overline{\dot{V}} \quad$ Averaged velocity vector in 2D $(x, y)$

$502 e \quad$ Aperture

$503 \rho \quad$ Fluid density

$504 \quad Q \quad$ Flow rate

$505 \quad w \quad$ Fracture width

$506 \quad \mu \quad$ Dynamic viscosity of fluid

$507 \quad P=p+\rho g \quad$ Total pressure

$508 \quad p \quad$ Pressure

$509 \quad g \quad$ Acceleration of gravity

$510 \quad X^{\prime}, Y^{\prime}, Z^{\prime} \quad$ Global coordinate system

$511 x, y, z$ Discontinuity oriented coordinate system

$512 \quad \overline{\bar{T}} \quad$ Stress tensor

$513 \quad D_{n}, D_{m} \quad$ Normal deformation at time n, maximum deformation

$514 \quad u, v \quad x$ and $y$ direction components of averaged velocity vector

$515 \quad K_{i} \quad$ Initial joint normal stiffness 
$516 \quad I, J \quad$ Main grid indices

$517 \quad i, j \quad$ Staggered grid indices

$518 \quad \phi, M, H \quad$ Variables used to replace expressions

$519 F_{u}, F_{l}$ Upper rock fracture profile and lower rock fracture profile in 3D space 


\section{List of Figures}

Fig. 1: Two-dimensional fracture flow modelling methods

Fig. 2: Irregular surface rock joint with fluid flow

Fig. 3: Flow domain discretisation

Fig. 4: Flow chart of SIMPLE algorithm coupled with deformation calculations

Fig. 5: Rock sample enclosed in polyurethane membrane and mounted on tri-axial apparatus

Fig. 6: Experimental set up

Fig. 7: (a) Scanning surfaces to measure aperture. (Height of silicon rubber is exaggerated for better view), (b) Silicon rubber sitting on lower half of rock sample to scanning.

Fig. 8: Aperture scanning procedure. (i) Remove top half. (ii) Scan silicon rubber surface. (iii) Remove silicon rubber. (iv) Scan lower half surface.

Fig. 9: Velocity and aperture plot for 3 stages of confining pressure in $40 \mathrm{kPa}$ inlet pressure tests. (a) $750 \mathrm{kPa}$ (b) $1000 \mathrm{kPa}$ (c) $1750 \mathrm{kPa}$

Fig. 10: Velocity and pressure distribution plot for $40 \mathrm{kPa}$ inlet pressure test at $1000 \mathrm{kPa}$ confining stress.

Fig. 11: Figure 11: Flow rates obtained in triaxial experiments and those predicted numerically for sandstone sample with a sub-axial fracture and the associated Reynolds numbers 
2D modelling from top view of the fracture

- Bear (1993)

- Kishida et al (2013)

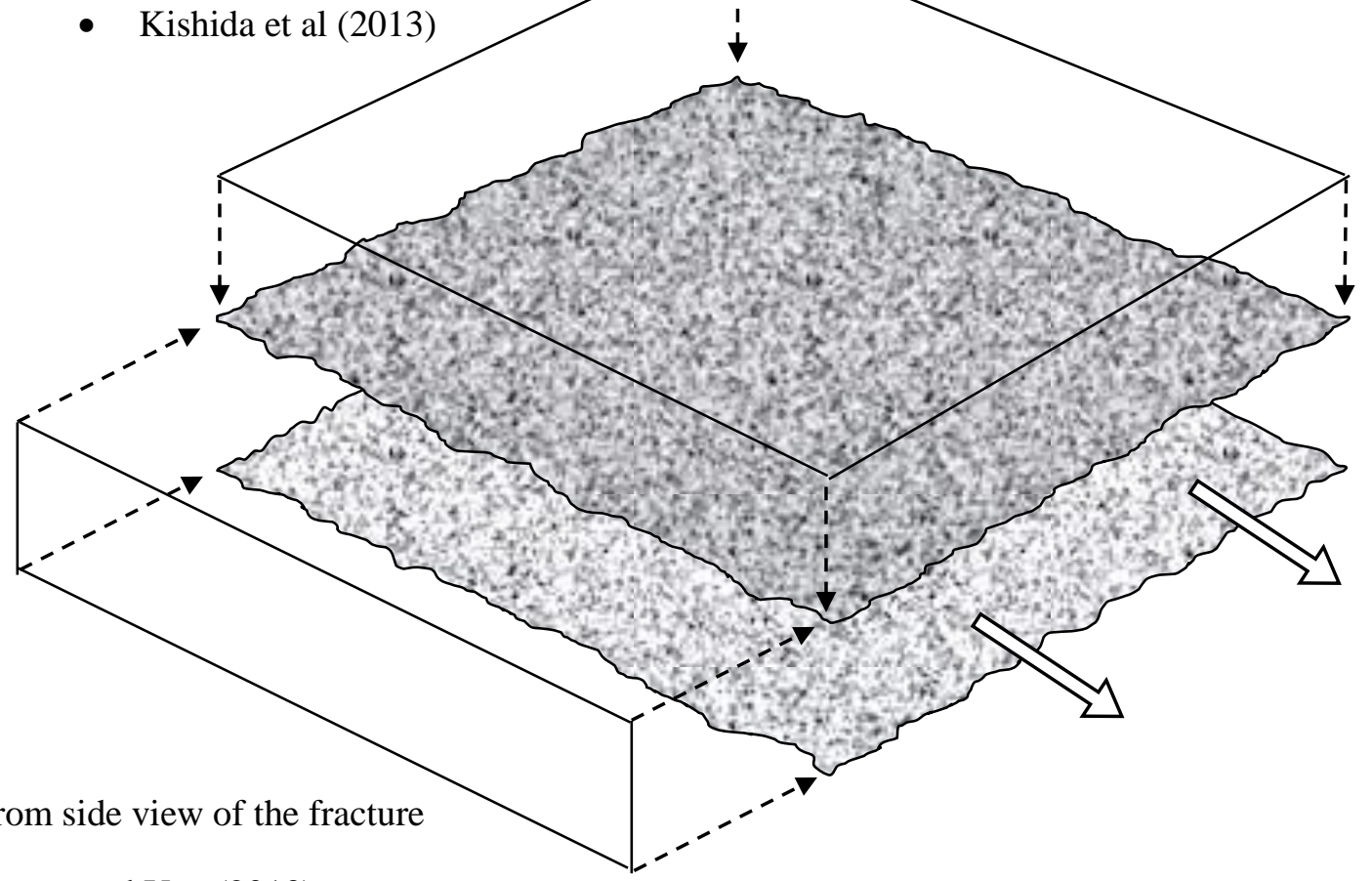

- Zimmerman and Yeo (2013)

- Koyama (2007)

- Indraratna et al., (2002)

- Price \& Indraratna (2005)

Fig. 1: Two-dimensional fracture flow modelling methods 


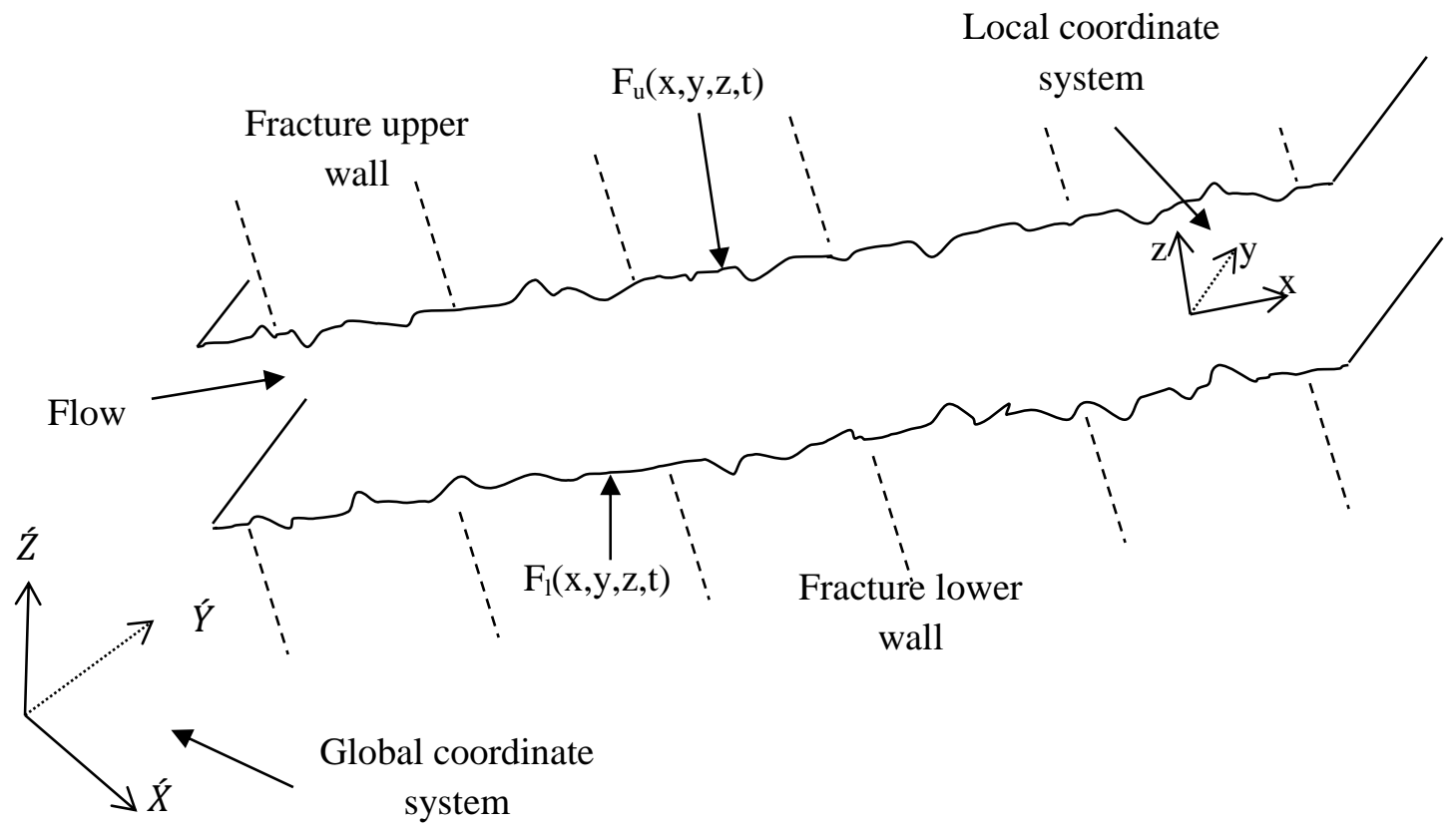

Fig. 2: Irregular surface rock joint with fluid flow 


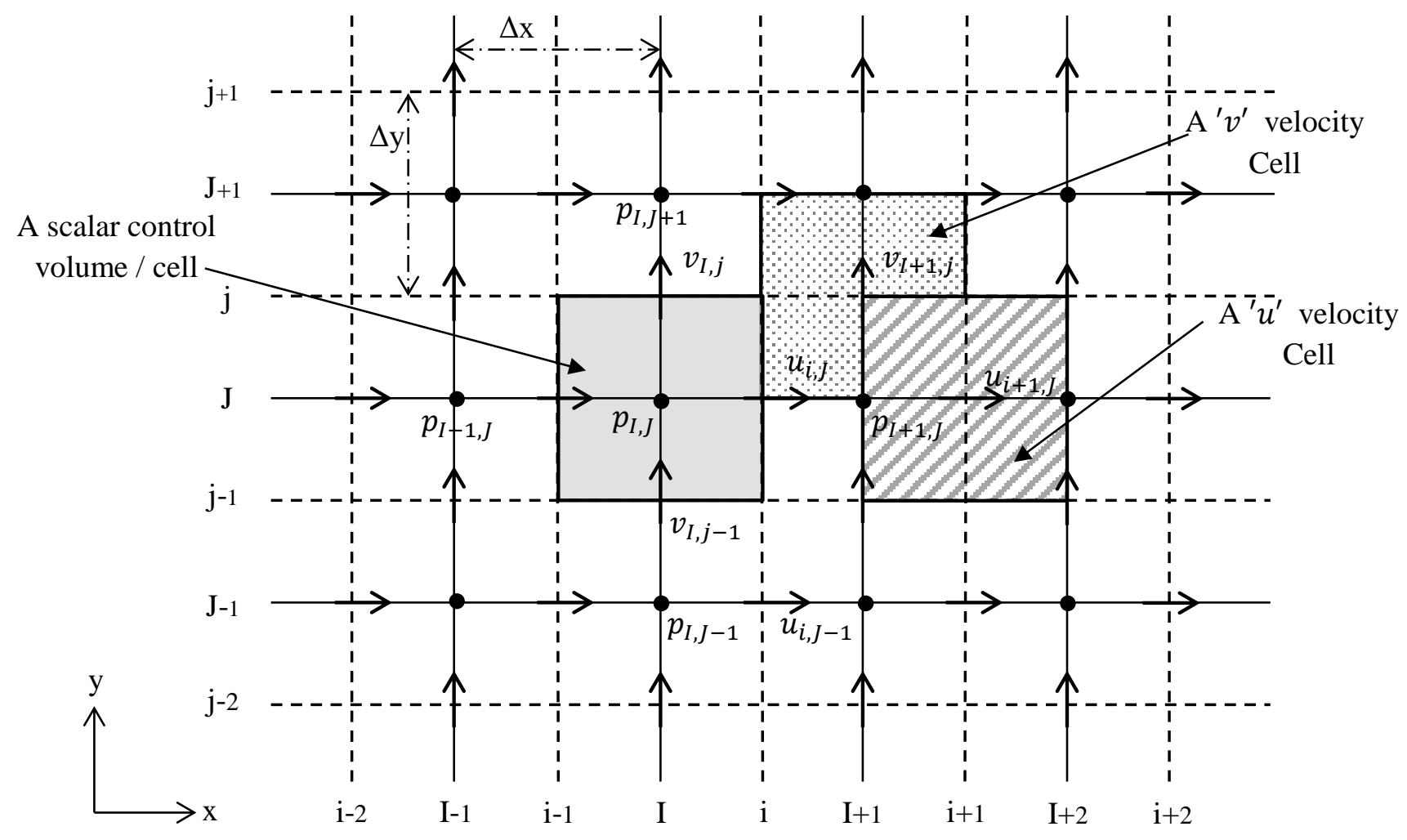

Fig. 3: Flow domain discretisation 


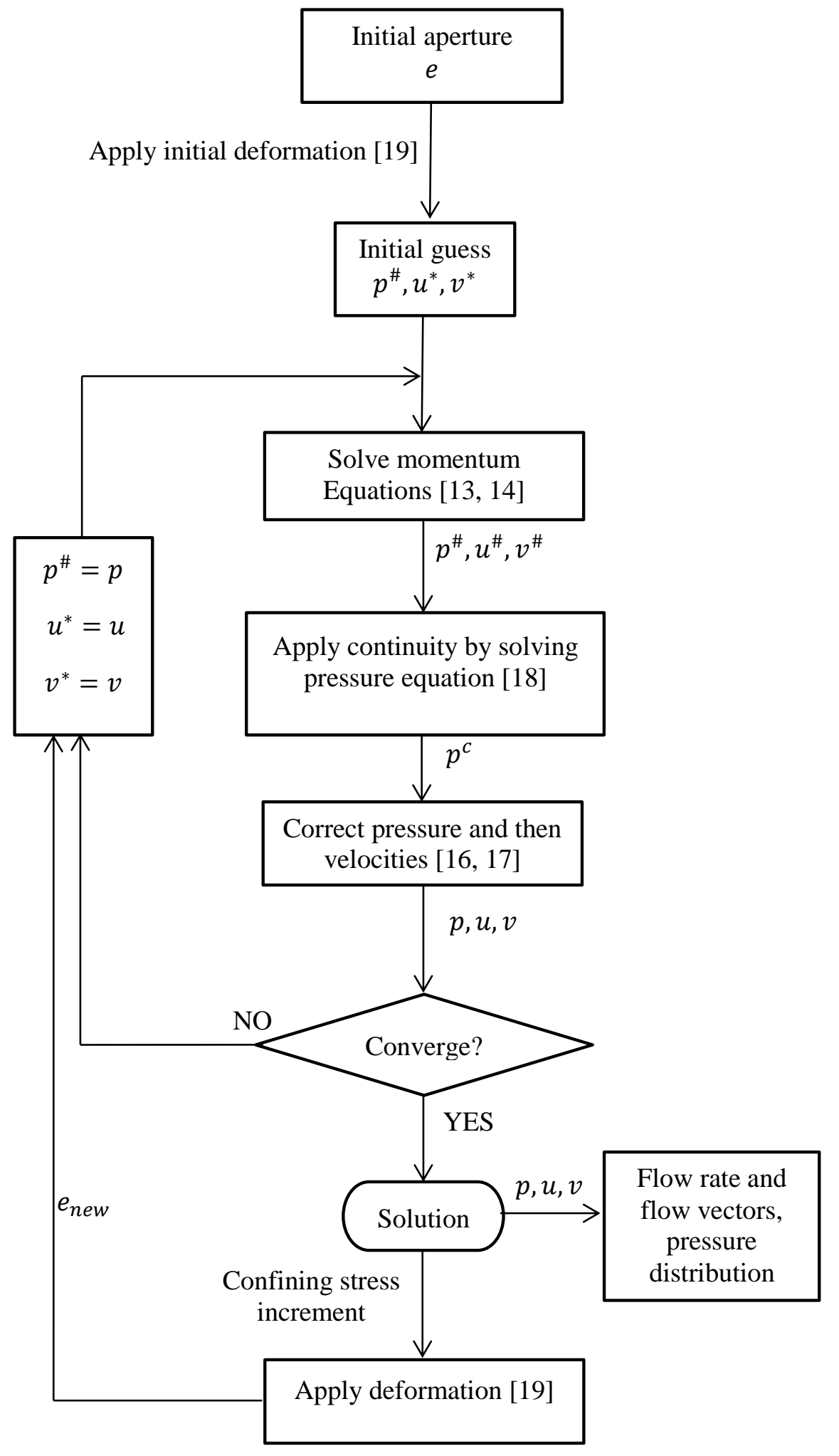

Fig. 4: Flow chart of SIMPLE algorithm coupled with deformation calculations 


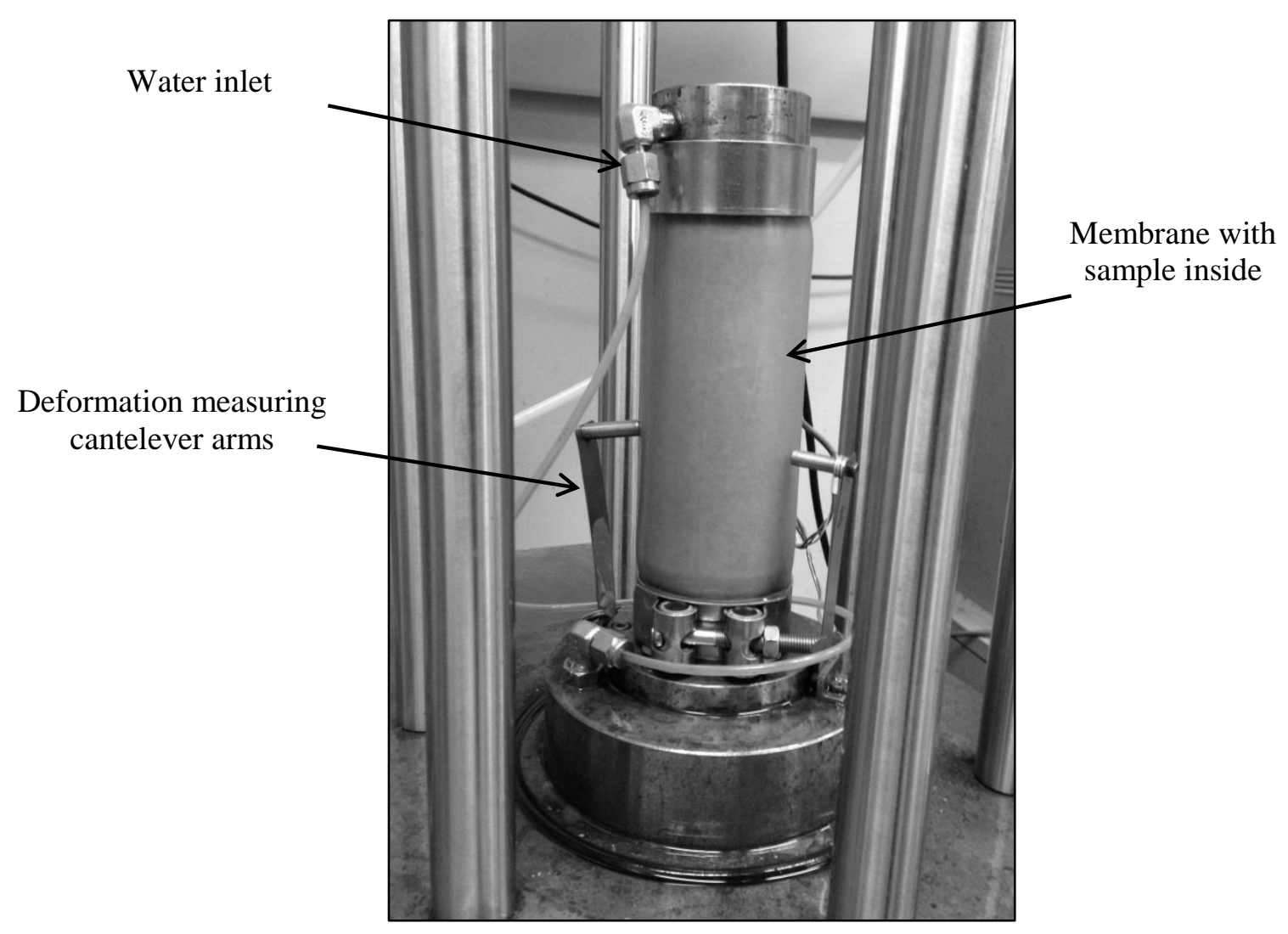

Fig. 5: Rock sample enclosed in polyurethane membrane and mounted in triaxial apparatus 


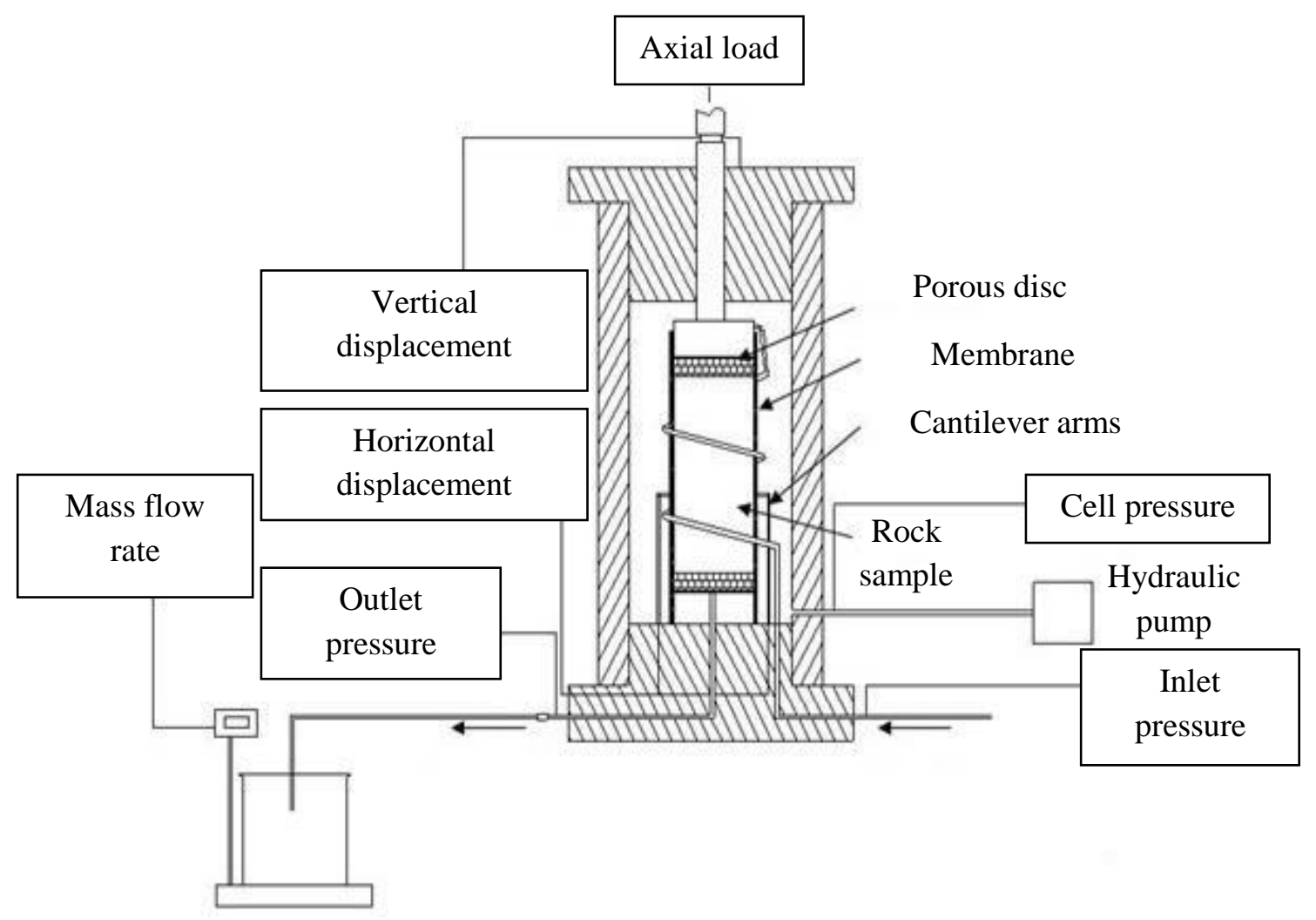

Fig. 6: Experimental set up 


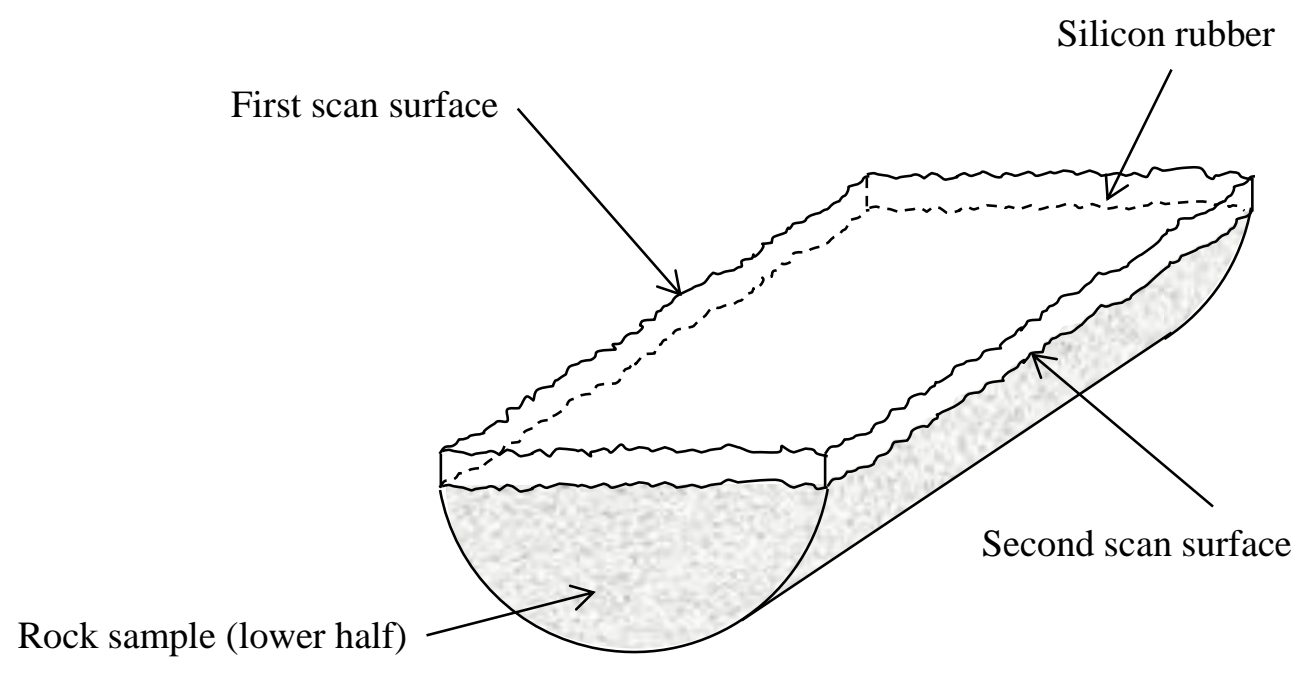

(a)

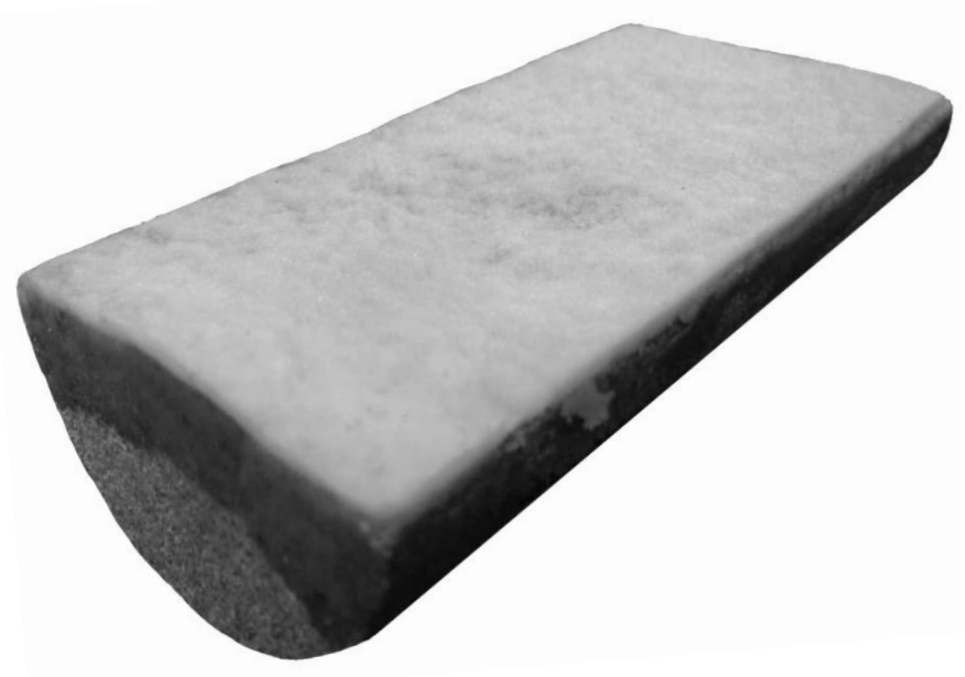

(b)

Fig. 7: (a) Scanning surfaces to measure aperture (height of silicon rubber is exaggerated for better view), (b) Silicon rubber sitting on lower half of a rock sample for scanning. 


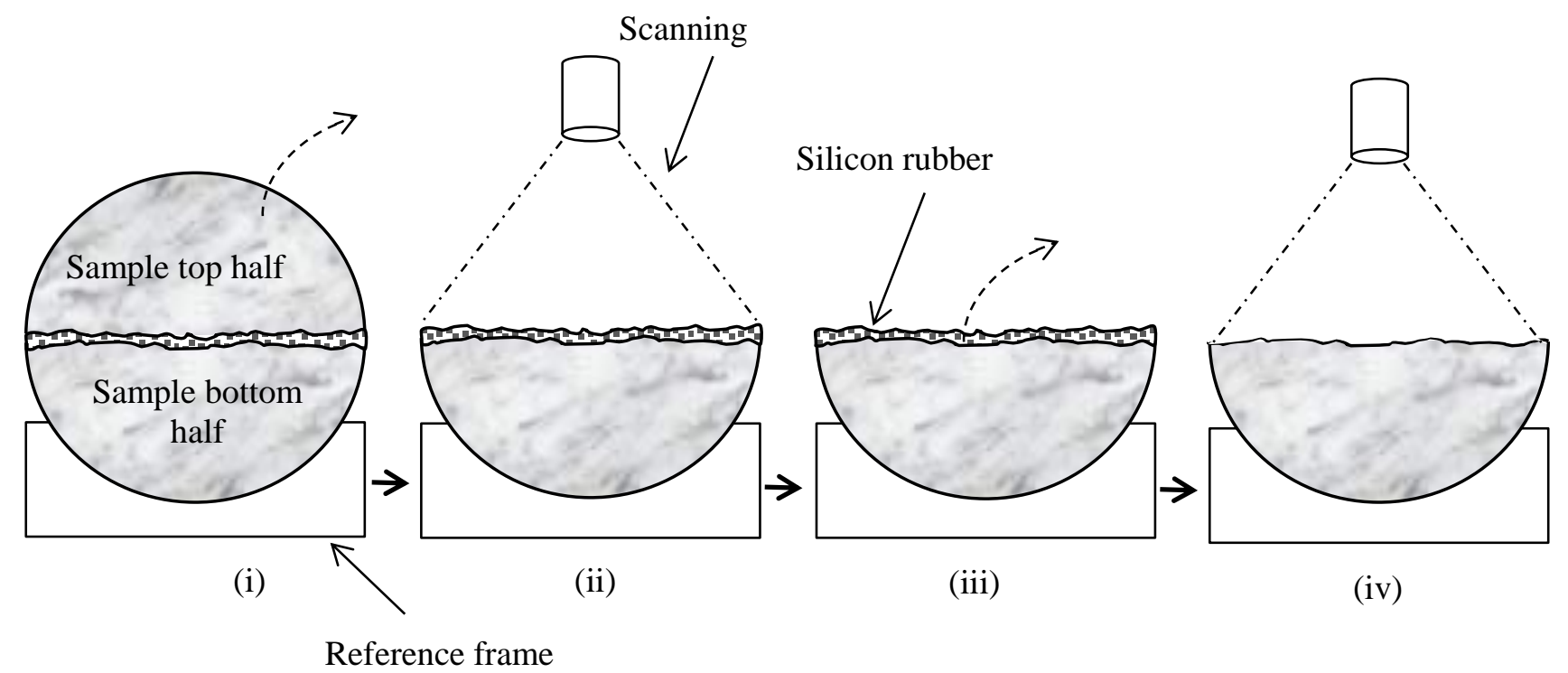

Fig. 8: Aperture scanning procedure. (i) Remove top half. (ii) Scan silicon rubber surface.

(iii) Remove silicon rubber. (iv) Scan lower half surface. 


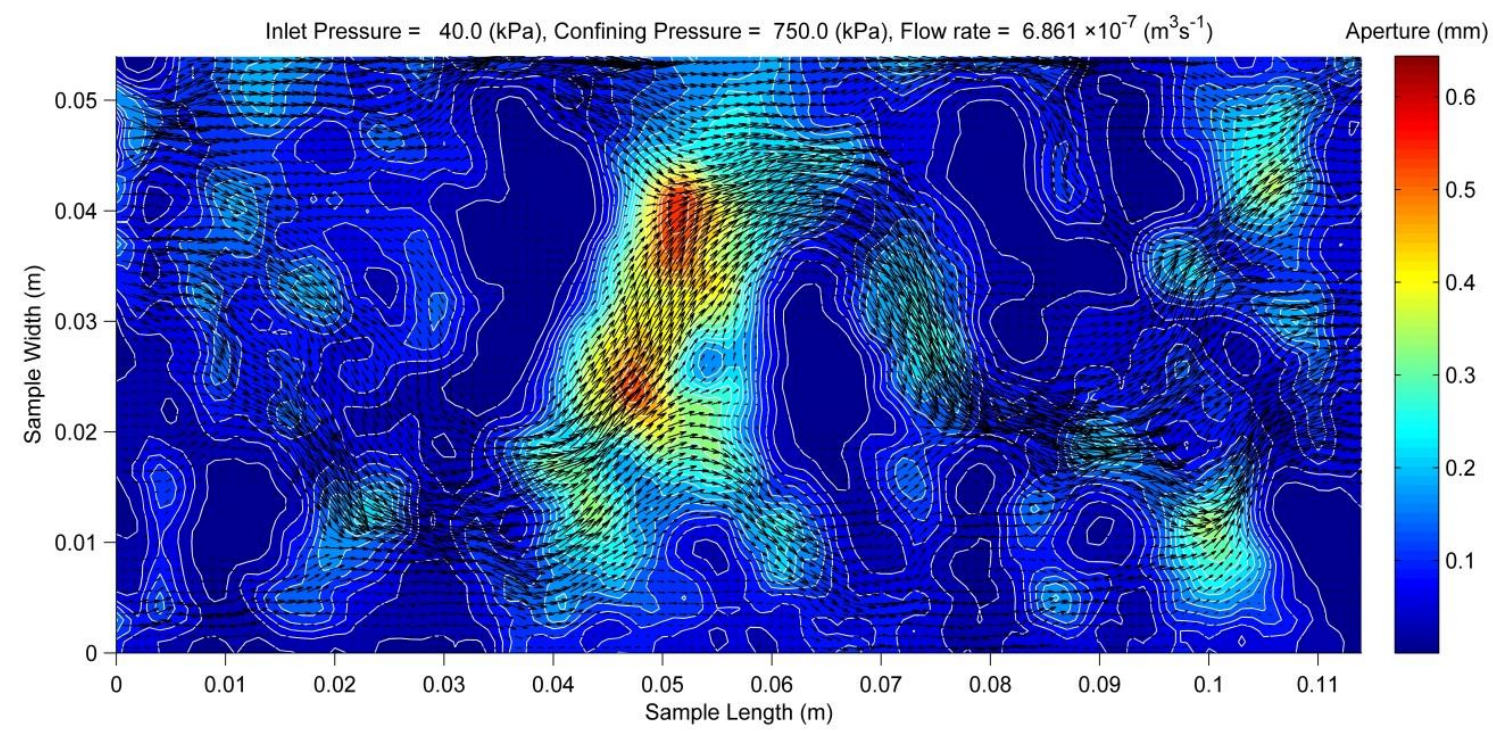

(a)

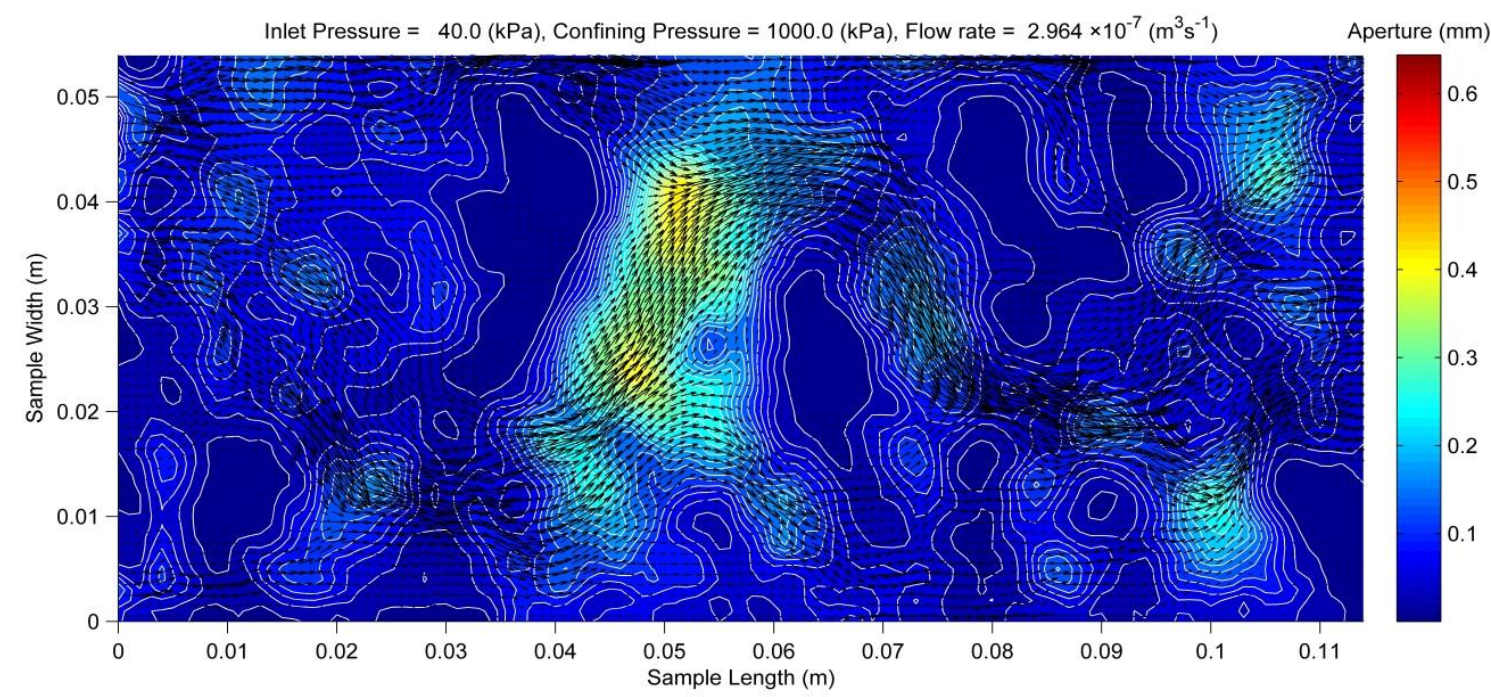

(b)

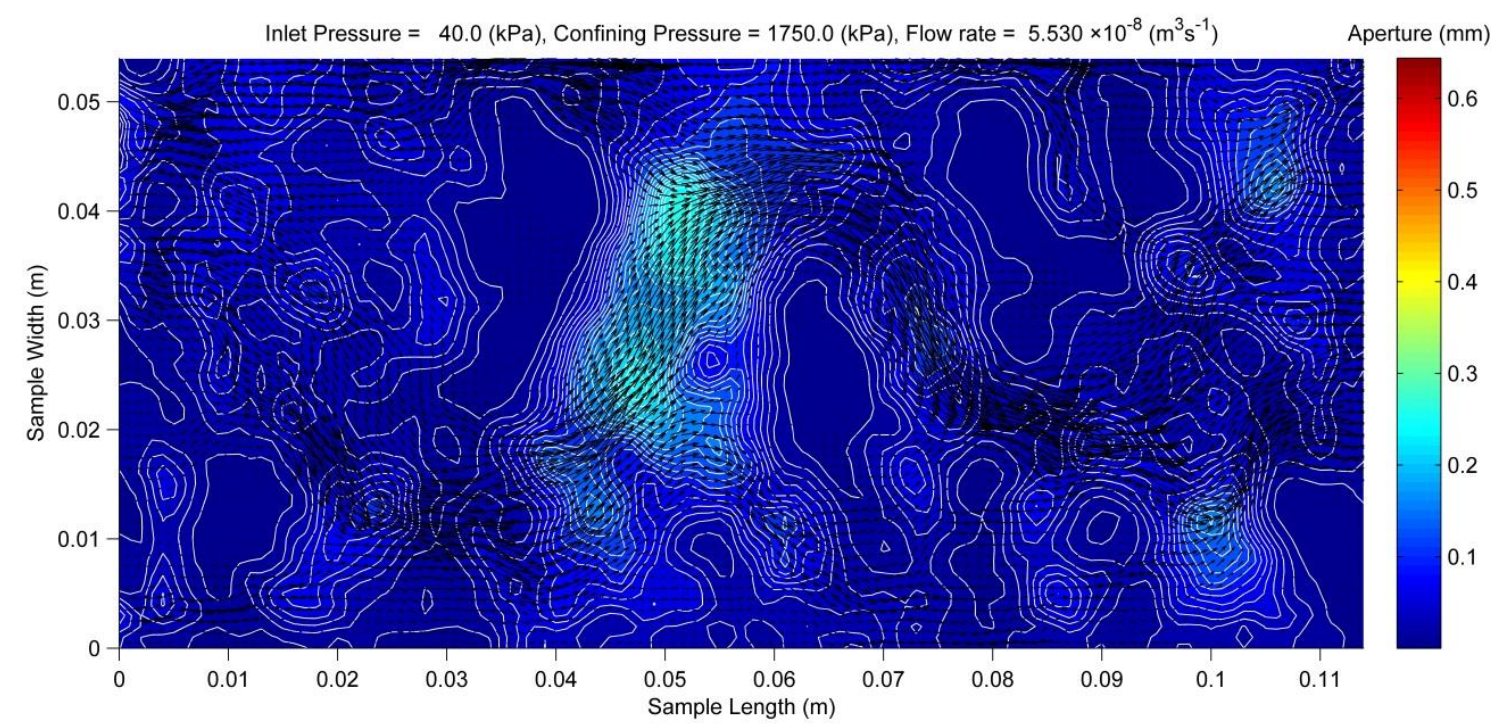

(c)

Fig. 9: Velocity and aperture plot for 3 stages of confining pressure in $40 \mathrm{kPa}$ inlet pressure tests (a) $750 \mathrm{kPa}$, (b) $1000 \mathrm{kPa}$, and (c) $1750 \mathrm{kPa}$ 


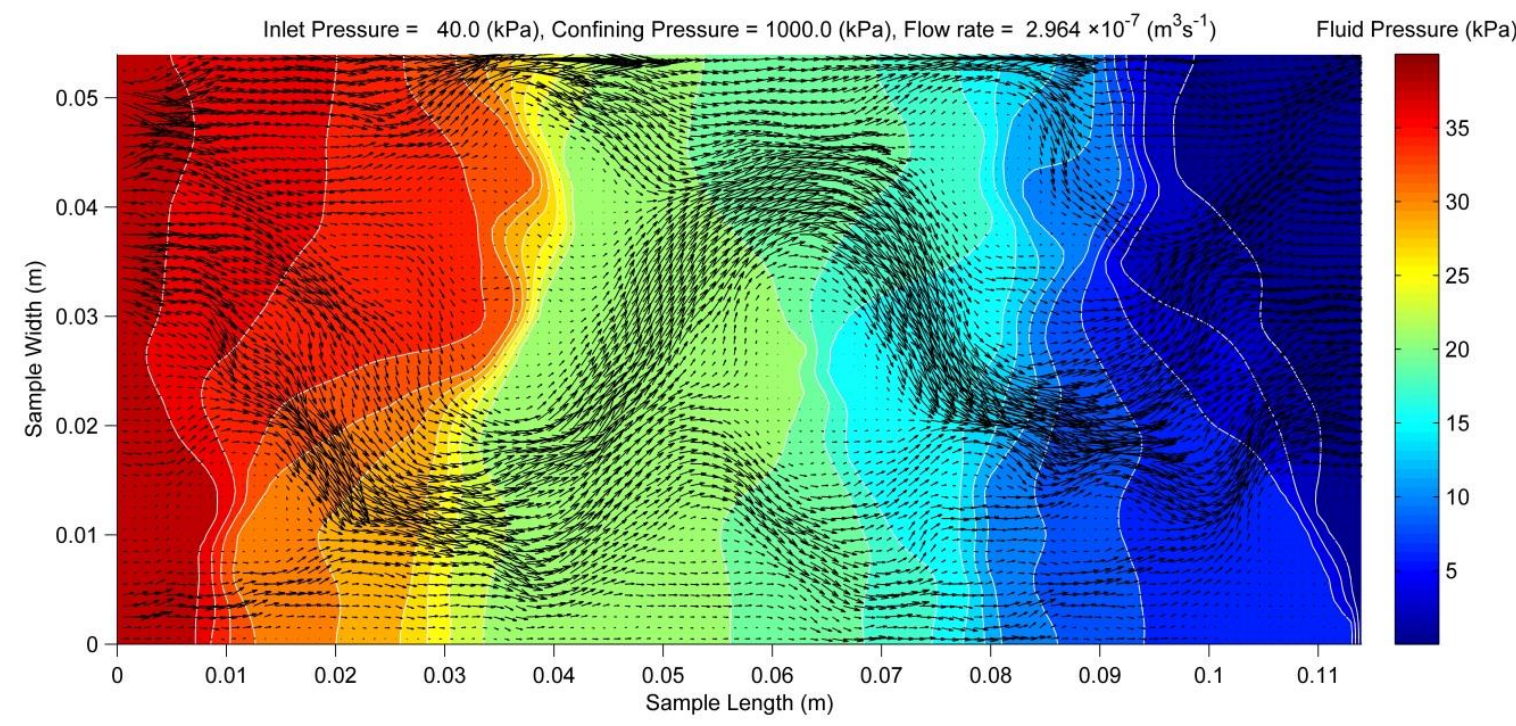

Fig. 10: Velocity and pressure distribution plots for $40 \mathrm{kPa}$ inlet pressure and at $1000 \mathrm{kPa}$ confining stress. 


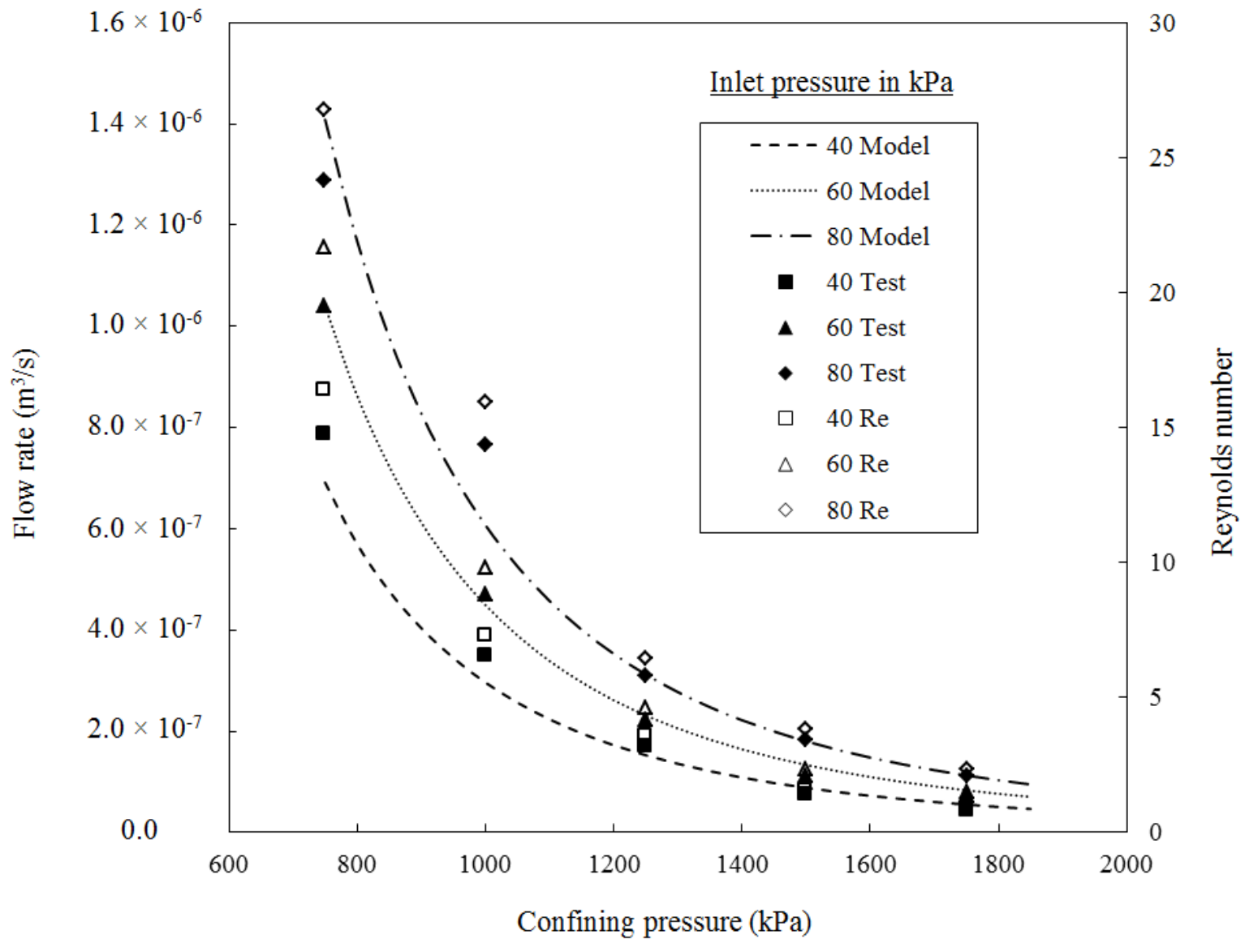

Fig. 11: Flow rates obtained in triaxial experiments and those predicted numerically for sandstone sample with a sub-axial fracture and the associated Reynolds numbers 